\title{
Evaluating ethical sensitivity in medical students: using vignettes as an instrument
}

\author{
Philip Hébert, Eric M Meslin, Earl V Dunn, Niall Byrne and S Ross Reid University of Toronto, Canada
}

\section{Authors' abstract}

As a preliminary step to beginning to assess the usefulness of clinical vignettes to measure ethical sensitivity in undergraduate medical students, five clinical vignettes with seven to nine ethical issues each were created. The ethical issues in the vignettes were discussed and outlined by an expert panel. One randomly selected vignette was presented to first, second and third year students at the University of Toronto as part of another examination. The students were asked to list the issues presented by the patient problem. Responses from 281 students were obtained. These students identified an average of 2.72 ethical issues per vignette. Each response was classified under the domains of autonomy, beneficence and justice. Comparisons were made between classes and between vignettes. There was considerable variation between classes and the responses to different vignettes seem to indicate that different vignettes measure the various domains in different ways. It does appear that the use of vignettes is one way to measure aspects of ethical sensitivity in medical students but more study is required to clarify exactly what is being measured.

\section{Introduction}

Many universities, including the University of Toronto, have begun to teach courses and conduct rounds and workshops related to ethical issues for medical students and postgraduate trainees $(1,2,3,4)$. Although there is some literature indicating that ethics can be taught, there is little research in the literature supporting the idea that teaching strategies actually increase students' sensitivity to and response towards ethical dilemmas. Before any attempt can be made to assess ethical sensitivity, instruments need to be developed which can measure aspects of ethical thought and behaviour. At the University of Toronto a group of five individuals convened at the request of the Undergraduate Medical Curriculum Committee to develop and test such an instrument. This group

\section{Key words}

Teaching medical ethics. focussed on an instrument to assess one aspect of ethical sensitivity in medical students: the ability to recognise ethical issues. The group consisted of an educational psychologist, an individual with a doctorate in philosophy specialising in bioethics, and three physicians - one anaesthesiologist/critical care physician, one family physician, and one family physician with a doctorate in philosophy. All these members had an interest in and some knowledge of medical education and ethics.

Few papers report on evaluation of ethics teaching. A search of the computerised database BIOETHICSLINE conducted in December 1989 using the keywords: 'Teaching medical ethics'; 'Evaluation'용 'Curriculum' and 'Teaching methods' provided $13 \%$ references. There are only two reports of instrument? used to evaluate ethical sensitivity $(5,6)$, and none were found that evaluated ethical sensitivity of undergraduate medical students using vignettes.

\section{Method}

To assess whether the ability of medical students to recognise ethical issues could be measured, five vignettes with ethical dimensions were developed by the group. These vignettes were related to the topics of infertility counselling in a retarded couple; care of a patient with a massive brain haemorrage; an 82-yearold woman with delirium, a patient with HIV positivity, and a depressed man with a malignant lump. The research group discussed these and developed a list of ethical issues associated with each vignette. The number of issues identified by this panel ranged from seven to nine per vignette. (A representative vignette and its analysis is included in appendix A.) These vignettes were submitted to some students in each of the first, second, and third year medical classes of the University of Toronto's four-year medical programme. Each student in attendance, randomly, received one of the vignettes to which to respond. The students were asked to list all the ethical $\stackrel{\infty}{?}$ issues related to the case they received. The response was voluntary. The number of students failing to respond was not recorded. A total of 281 responses were received: 74 from year I ( 26 per cent of the total respondents), 120 from year II (43 per cent), and 87 from year III ( 31 per cent). 
Each vignette was scored by one investigator as to the number of issues the student identified, regardless of the content of the response. For purposes of analysis, the identified issues were classified under the domains of autonomy, beneficence, and justice. These principles have been extensively developed elsewhere for discussions in bioethics (7). Interobserver reliability checks were done on the scores of the five investigators to ensure conformity of coding. Pearson correlations, by pairs of observers, ranged from 0.89 to 0.94 . The purpose of this project was to test the feasibility of this method to evaluate one aspect of ethical sensitivity. Interpretation of these data is tentative as will be discussed below. Nonetheless, as an aid to decide whether this method had potential to assess ethical sensitivity, the following analyses were done.

\section{Results}

The ethical sensitivity of the students varied considerably as measured by this method. The number of issues identified averaged 2.72 (SD 1.22) for all vignettes and all students. The range by student was from 0 to 7 (maximum for the panel was 9). The three different years all had good dispersion of responses (year I 0-6, year II 1-7, year III 0-5). The frequency distributions of the number of issues identified for all students and by medical class all approximate a normal curve.

\section{DIFFERENCES BY MEDICAL CLASS}

Table I displays the summary scores for all vignettes by year. The second year class had the highest average number of issues identified, 3.13, with year I averaging 2.35 and year III 2.46. These were 39 per cent, 30 per cent and 31 per cent of those identified by the panel, respectively. The differences between year II and the other classes were statistically significant $(p<\cdot 001)$. These differences are enhanced at the limits of the range. For example, although the second year class had 43 per cent of the respondents, only eight of the 40 individuals identifying 0 or 1 issues were from the second year class whereas 17 of the 21 students identifying five or more issues were from the second year. The second year class identified the least number of autonomy issues $(p=.07)$ and identified the most in both the beneficence $(p<.001)$ and the justice $(p>.2)$ domains. These differences were consistent by question except for vignette number 4 , the HIV positivity vignette.

\section{DIFFERENCE BY VIGNETTE}

Table II summarises the results by vignette. Although the pattern of response by class in relation to the three domains seemed to be relatively consistent by vignette (with the possible exception of vignette 4), there were considerable differences in response by vignette. For example, the percentage of issues in the justice domain identified by the students varies from slightly under 6 per cent for vignette 5 (a 45-year-old depressed man with a malignancy) to over 60 per cent for vignette 4 (an individual with HIV positivity). For the same domain, the second year class varied from 5 per cent to 70 per cent between vignettes 5 and 4 .

The third year class appeared to have the largest variation between vignettes for the identification of the ethical issues ( 23 per cent to 44 per cent for autonomy, 8 per cent to 36 per cent for beneficence and 6 per cent to 54 per cent for justice). Although the students were only asked to list the ethical issues, medical issues were

TABLE I

ISSUES IDENTIFIED BY CLASS YEAR

(Per cent of issues identified by the panel)

$\begin{array}{lllll} & \begin{array}{l}\text { TOTAL } \\ \mathrm{N}=281\end{array} & \begin{array}{l}\text { YEAR I } \\ \mathbf{N}=74\end{array} & \begin{array}{l}\text { YEAR II } \\ \mathbf{N}=120\end{array} & \begin{array}{l}\text { YEAR III } \\ \mathbf{N}=87\end{array} \\ \text { TOTAL }^{\star} & .34(2.72) & .30(2.35) & .39(3.13) & .31(2.46) \\ \text { AUTONOMY } & .37(1.02) & .41(1.15) & .34(0.93) & .37(1.02) \\ \text { BENEFICENCE } & .33(0.94) & .21(0.59) & .47(1.33) & .23(0.68) \\ \text { JUSTICE } & .29(0.77) & .23(0.61) & .32(0.87) & .29(0.76) \\ \text { MEDICAL } \star & .37 & .30 & .35 & .45\end{array}$

* TOTAL $=$ AUTONOMY + BENEFICENCE + JUSTICE

$\star \star$ MEDICAL ISSUES PER VIGNETTE

( ) = AVERAGE NUMBER OF ISSUES IDENTIFIED 


\section{TABLE II}

\section{ISSUES IDENTIFIED BY VIGNETTE}

(Per cent of issues identified by the panel)

\begin{tabular}{|c|c|c|c|c|c|}
\hline & $\begin{array}{l}\text { No } 1 \\
N=53\end{array}$ & $\begin{array}{l}\text { No } 2 \\
N=63\end{array}$ & $\begin{array}{l}\text { No } 3 \\
N=57\end{array}$ & $\begin{array}{l}\text { No } 4 \\
\mathrm{~N}=54\end{array}$ & $\begin{array}{l}\text { No } 5 \\
N=54\end{array}$ \\
\hline TOTAL * & .31 & .31 & .34 & .47 & .28 \\
\hline AUTONOMY & .24 & .35 & .39 & .44 & .41 \\
\hline BENEFICENCE & .30 & .31 & .41 & .31 & .29 \\
\hline JUSTICE & .39 & .25 & .16 & .60 & .06 \\
\hline 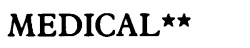 & .42 & .29 & .47 & .41 & .26 \\
\hline
\end{tabular}

\section{$\star$ TOTAL $=$ AUTONOMY + BENEFICENCE + JUSTICE $\star \star$ MEDICAL ISSUES PER VIGNETTE}

identified. As might be expected the number increased as the class year increased (Table I).

\section{Discussion}

Basic curricular goals in medical ethics teaching for medical schools have been identified and recommended (1). Bioethics is now an established part of teaching in many of the health science curricula across the continent (2). Most Canadian medical schools currently teach bioethics, with medical students being exposed to between eight and thirty hours of classes in their undergraduate years (3). A recent American review of ethics teaching suggests that such teaching in a professional school like medicine should be integrated into the rest of the curriculum and should combine ways of imparting elements of moral knowledge and behaviour, value recognition and virtue (4). Just how this integration might best be done has yet to be agreed upon.

Formal courses in ethics in professional schools have met with varying degrees of success. Although greeted with initial enthusiasm and interest, continuation in the curriculum has meant that such courses must demonstrate their effectiveness or risk losing valuable curricular hours to ostensibly more clinically relevant subjects. One way of assuring curricular access is to demonstrate that medical ethics is a teachable course that can be evaluated in a formal fashion. Evaluation is not the ultimate goal (8), but it can help tell us whether we are achieving some of our goals in offering ethics to medical students (9). There will be much that is central to ethics that cannot be easily captured by measuring instruments, for example attitudes, skills, etc. Nonetheless the introduction of new and timely techniques of imparting ethics to trainees should not await the torporous task of course evaluation.
The instrument used in this study proposed to evaluate one component of ethics, the ability to recognise an ethical issue. While this can hardly be said to exhaust the educational objectives of a course is medical ethics, it is a reasonable place to begino Developing the ethical sensitivity of medical students depends on students recognising the existence of ethical issues. All of the students participating in this study had the benefit of a brief formal course in ethics in their first year of medical school. One central objective of this course is to help students identify ethical issues in medicine. Thereafter, training in ethics is done at the discretion of interested instructors in the medical school and through innovative programmes at several of the University of Toronto teaching hospitals. Acknowledging the ad hoc nature of teaching medical ethics to medical students following their required first year course, work has begun on developing a unified curriculum for ethics in the later years of the undergraduate medical degree.

The results of this study suggest that an evaluation tool using vignettes can discriminate among students in terms of their ability to recognise ethical issues. There was a normal distribution for all students and classes with a low mean score of 30 to 39 per cent. The tenuous circumstances under which the instrument was administered means that no conclusions about the reliability of the specific results can be drawn. The response rate appeared to be much better in one year because the supervisor of the course where the vignette was inserted was more committed to the ethics course. The overall response rate was relatively low, perhaps because participation was voluntary and because the testing was done immediately prior to the year-end examinations. This as well may have influenced the overall low scores. Finally, administering the 
instrument close to high-pressure examinations may hardly be the best time. Thus, whether the specific differences and similarities in terms of ethical recognition observed between the medical years were veridical or not is not something we can comment upon. We hope to address these problems in the future so that more reliable conclusions about the ethical development of medical students can be drawn. Work is now underway to modify the initial instrument and the conditions under which it was administered to capture more accurately medical student ethical sensitivity.

Finally, and rerhaps most importantly, there are other aspects of morality involving attitudes, skills, facts, and formal knowledge (10) which this type of instrument cannot evaluate. Future endeavours in this area should seek to develop tools for assessing some of the more praxis-oriented aspects of ethics (11).

\section{Next steps}

Many of the problems we have identified are to be addressed in follow-up studies so that more reliable conclusions about the ethical sensitivity of medical students can be drawn. The following steps are planned: 1) to modify the initial instrument and give the test to a similar group of medical students. Modifications will include providing for a better sampling of the whole class in each of the years evaluated, controlling the potential for bias by instructors who either under- or over-emphasise the instrument's importance, increasing the number of vignettes tested, using a programmed series of vignettes, and administering the vignettes at an earlier point in the year; and, 2) to develop a similar instrument to compare the ethical sensitivity of the years I-III students with that of year IV students. Since ethical sensitivity may be a relative rather than an absolute notion, it will be important to determine not only whether knowledge of ethical concepts and skills have been retained in the first three years of medical education, but also whether they are being usefully applied in the clinical environment. It is already known that physicians who have had courses in medical ethics have perceived them to be of substantial practical value (12).

\section{Conclusions}

The methodology used in this project to evaluate the ethical sensitivity of medical students is preliminary. As a result, no definite conclusions can be drawn about the students' sensitivity to ethics. However, the use of vignettes may be one feasible method to show differences between medical students in the way they identify ethical issues. Because of the differences between the responses to the different vignettes, it is probable that more than one vignette would be necessary to do an adequate assessment of an individual's ethical sensitivity. As well, vignettes are best suited to capturing the cognitive ability to recognise an ethical issue. Other aspects of ethical sensitivity will require other instruments in order to be evaluated. The development of such instruments should not delay educators from the timely task of engendering imaginative forms and means of teaching biomedical ethics to medical students.

Philip Hébert PhD, MD, is Assistant Professor, Department of Family and Community Medicine, Faculty of Medicine, University of Toronto. Eric M Meslin PhD, is Bioethicist at the Clinical Ethics Centre, Sunnybrook Health Science Centre and Assistant Professor in the Department of Philosophy, University of Toronto. Earl V Dunn MD, is Professor in the Department of Family and Community Medicine, Faculty of Medicine, University of Toronto. Niall Byrne PhD, is Associate Professor at the Centre for Studies in Medical Education, Faculty of Medicine, University of Toronto. S Ross Reid MD, FRCPC, is Assistant Professor in the Department of Anaesthesia, Faculty of Medicine, University of Toronto. Address reprint requests to Dr Philip Hebert, Sunnybrook Health Science Centre, 2075 Bayview Avenue, Toronto, Ontario, M4N 3M5.

\section{References}

(1) Culver C, Clouser K D, Gert B, Brody H, Fletcher J, Jonsen A, Kopelman L, Lynn J, Siegler M, Wikler D. Basic curricular goals in medical ethics. New England journal of medicine 1985; 312: 253-256.

(2) Towards a Canadian research strategy for applied ethics. A Report by the Canadian Federation for the Humanities to the Social Sciences and Humanities Research Council of Canada. Ottawa, 1989, May: 31.

(3) Williams J. Biomedical ethics in Canada. Queenston, Canada: Edwin Mellen Press, 1986.

(4) Caelleigh AS, Lane LW, Miles SH, eds. Special issue: teaching medical ethics. Academic medicine 1989; 64: 699-764.

(5) Stolman C J. The development and validation of a test instrument for assessing value preferences in medical ethics. PhD dissertation, Ann Arbor Michigan: University Microfilms, 1981.

(6) Olukoya A A. A workshop on medical ethics at the College of Medicine, Lagos University. Fournal of medical ethics 1984; 10: 199-200.

(7) Beauchamp T L, Childress J F. Principles of biomedical ethics (3rd ed). New York: Oxford University Press, 1989.

(8) Schwandt T. Evaluating the medical humanities. Teaching and learning in medicine 1989; 1: 122-127.

(9) Spooner H J, Haight K R, Emson H E, To T. Assessment of medical students' learning and performance in an introductory medical ethics course. Teaching and learning in medicine 1989; 1: 167-170.

(10) Wilson J, Williams N, Sugarman B. Introduction to moral education. Baltimore: Penguin Books, 1967.

(11) Rest J. A psychologist looks at the teaching of ethics. Hastings Center report 1982; 1: 29-36.

(12) Pellegrino E D, Hart R J, Henderson S R, Loeb S E, Edwards G. Relevance and utility of courses in medical ethics: a survey of physicians' perceptions. Fournal of the American Medical Association 1985; 235: 49-53. 


\section{APPENDIX A - A SAMPLE VIGNETTE.}

\section{The format of the question to the students}

For the following patient scenario, please list, in point form, those issues which you think are important to the ongoing management of the patient. Remember that it is not necessary to complete this question and, whether or not it is completed, it will not, in any way, contribute to your marks or evaluation.

You visit, at home, an 82-year-old female patient who has been previously healthy and independent. She has been deteriorating for five weeks. She has lost weight, is mildly delirious, and has taken to her bed. You think she needs to come into hospital for further investigations of this. She adamantly refuses.

\section{The standard used for the evaluation of this vignette.}

The issues for this vignette were collected under the domains of autonomy, beneficence and justice. A student received a mark for each time she or he broadly recognised one of the issues listed below:

I. Autonomy - respect for patient wishes and confidences

- the question of the patient's competence

- suggest aim to restore autonomy

II. Beneficence - assist those at risk

- prevent harm

- provide appropriate medical treatment - either at home or in hospital

III. Justice

- distribution of resources to the elderly

- obtain social or other services

- interests and wishes of family and friends

Each domain was marked out of 3 with a total possible score of 9.

News and notes

Tenth International Congress on Medical Informatics, MIE 91

The Tenth International Congress on Medical Informatics, MIE 91, will be held in Vienna, Austria from August 19th-22nd 1991.

Topics include: health care systems, information systems, expert systems and decision-making, legal and ethical issues, biomedical engineering and network systems in health care.

The conference aims to promote all aspects of medical informatics and health care computing.

Correspondence to: MIE 91, Interconvention, A-1450 Vienna, Austria. Telephone: (43) (222) 23 69-2641; Telex: 1118 03; Telefax: (43) (222) 23 69-648. 